EPiC Series in Engineering
Volume 3, 2018, Pages 1876-1884
HIC 2018. 13th International
Conference on Hydroinformatics

\title{
Storm surge assessment methodology based on numerical modelling
}

\author{
Lara Santos ${ }^{1}$, Mariana Gomes ${ }^{1}$, Luís Vieira ${ }^{1}$, José Pinho ${ }^{1 *}$, José Antunes do \\ Carmo $^{2}$ \\ ${ }^{1}$ Department of Civil Engineering, University of Minho, 4710-057 Braga, Portugal \\ ${ }^{2}$ Department of Civil Engineering, University of Coimbra, 3030-788 Coimbra, Portugal \\ Corresponding author: jpinho@civil.uminho.pt
}

\begin{abstract}
.
Coastal zones face severe weaknesses and high-risk situations due to coastal threats like erosion and storms and due to an increasing intensive occupation. Tropical storms events can contribute to the occurrence of these situations, by causing storm surges with high water levels and, consequently, episodes of waves overtopping and coastal flooding. This work aims to describe a methodology to estimate the storm surge occurrences in the Portuguese coastal zone, recurring to historical tropical storms data that occurred in the vicinity of Portugal and to numerical modeling of its characteristics. Delft3D software together with DelfDashboard tools were applied for the numerical modelling. An automatic generation procedure of storms was implemented based on the few available historical storms data characteristics. Obtained results allows to characterize storm surges along the Portuguese coast, identifying the most vulnerable areas and, consequently contributing for its proper planning and management.
\end{abstract}

\section{Introduction}

Tropical storms and wind storms can affect coastal areas, causing various risky situations. These includes episodes of wave overtopping over coastal defences and dunes, coastal flooding due to abnormal storm surges combined with spring tides, coastal erosion and consequently loss of territory, resulting in countless damages including loss of property and human lives.

In the North Atlantic Basin (Fig. 1), tropical storms occur with a certain seasonality (mainly concentrated in August and September) and usually affect the Eastern United States and Canada (between 1 and 2 storms every year) and occasionally also Western Europe (1 storm in 1 or 2 years) (Hart and Evans, 2001; Keim et al., 2004). Regarding the storms that affected Western Europe, Portugal has an incidence of $22 \%$ (Hickey, 2011).

\footnotetext{
${ }^{*}$ Corresponding author
} 
For Portugal, the characteristic wind regime (according to the climatic data from ERA-40 for the period between 1957 and 2002) has a predominance towards the southern sector (43\%), with monthly average speeds between 4 and $5 \mathrm{~m} / \mathrm{s}$, whereas higher speeds, between 7.5 and $8.5 \mathrm{~m} / \mathrm{s}$, occur mainly for $\mathrm{NE}$ and $\mathrm{E}$ sectors $(2 \%)$ (ECMWF, 2012). The monthly average values of atmospheric pressure are primarily between 1015 and 1022 mbar, with a predominance of 1020 mbar (11\%) (ECMWF, 2012).

In terms of tide and wave climate, the west coast of Portugal is exposed to maximum tide heights of around $3.7 \mathrm{~m}$ and significant storm wave heights of about $9.5 \mathrm{~m}$ for a return period of 5 years (Ferreira and Dias, 1997). The Portuguese coast has a high variety of geomorphologic characteristics, dominated by beaches, cliffs and wetlands (estuaries and coastal lagoons). About $42 \%$ of the Portuguese coastal zone is located at low levels, corresponding to a set of transition systems and beaches (Dinis and Tavares, 2005), where the dune system (severely degraded in many locations due to dominant erosion trends) is the sole natural protection against potential storms. If for any occurrence, the frontal dune system is destroyed in some zones of great weakness, the flooding areas will be very broad, exposing urban areas close to the sea.

Previous hydrodynamic numerical studies for a winter storm affecting the central west coast of Portugal (Figueira da Foz, Murraceira island), clear showed that water levels are aggravated during the storm events increasing the flooded area in this situation when combined with the occurrence of high tide for spring tides. With sea level rise associated with climate change the effects of coastal storms become worse (Santos et al., 2012). Another study related with storm surge occurrences in the northeastern United States coast, in Battery, New York (Gomes et al., 2015) allows to simulate with reasonable approximation the storm surges levels at this coastal location.

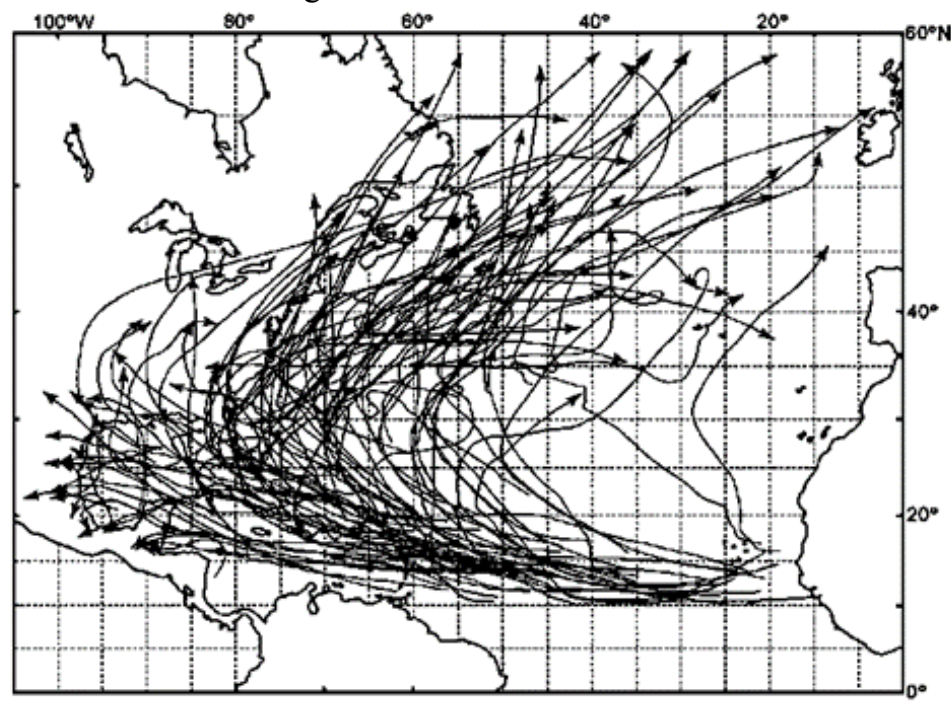

Figure 1: Typical tracking of tropical storms verified in the period from 1886 to 1992 (adapted from Neuman et al., 1993)

The main objective of this work is to present a methodology for studying storm surge occurrences in the Portuguese coast, based on hydroinformatic tools. The storms modeling framework is based on different data sources, on the DelftDasboard preprocessing tools and on Delft3D-FLOW. The work is based on the simulation of historical coastal storms that occurred near Portugal, allowing to estimate the storms effect on the water surface elevation along the coast. These results allow to identify the most vulnerable areas and contribute for the proper planning and management of Portuguese coastal regions. 


\section{Methodology}

The work considered three development stages. In the first stage, historical coastal storms that occurred near the Portuguese coast were collected, recurring to databases of the National Oceanic and Atmospheric Administration (NOAA, 2012), and adopting the Saffir-Simpson Scale.

In the second stage, considering historical storms characteristics a set of storms trajectories and intensities were defined and simulated in a hydrodynamic regional domain for the Iberian Peninsula implemented in Delft3D-FLOW (Deltares, 2011). Hydrodynamic simulations were carried out considering different physical phenomena, such as Coriolis force, tides, and currents induced by wind and pressure gradients. Wind fields and pressures were defined based on the storms characteristics and recurring to DelfDashboard tool that implements the spider-web wind field (Deltares DelftDashboard, 2012) associated with the storm. The Tropical Cyclone Toolbox that computes the wind field and pressure drop generated by a cyclone was used to simulate the wind fields associated with storm events. This tool is based on the wind enhanced scheme based on the analytical cyclone model of Holland (Holland, 1980) that was further improved by introducing asymmetry. Holland's model assumes that for a generic tropical cyclone, the surface pressure field follows a modified rectangular hyperbola, as a function of radius, given by:

$$
P(r)=P_{c}+\left(P_{n}-P_{c}\right) \exp ^{-\left(R_{\max } / r\right)^{B}}
$$

and the velocity $\mathrm{V}(\mathrm{r})$ at a distance $\mathrm{r}$ from the hurricane center, is:

$$
V(r)=\left[\frac{B}{\rho_{a}}\left(\frac{R_{\max }}{r}\right)^{B}\left(P_{n}-P_{c}\right) \exp ^{-\left(R_{\max } / r\right)^{B}}+\left(\frac{r f}{2}\right)^{2}\right]^{1 / 2}-\frac{r f}{2}
$$

where $\mathrm{Pn}$ is the ambient surface pressure, Pc is the hurricane central surface pressure, Rmax is the radius of maximum wind, $\mathrm{f}$ is the Coriolis parameter, $\mathrm{a}$ is the air density, and $\mathrm{B}$ is a hurricane-shape parameter (ranging from 1 to 2.5). The computed winds are then adjusted to account for the asymmetry introduced by the interaction of the cyclone with the steering flow by adding the translatory movement of the cyclone to the existing wind field. Other formulations are found in the literature, as per example (Madsen and Jakobsen, 2004), which also includes statistical forecast models for forecasting of the cyclone track and maximum wind speed and an uncertainty prediction procedure.

For a particular cyclone it is necessary to define its trajectory and associated time steps, maximum wind speed (Vmax), maximum radius wind speed (Rmax), and pressure drop (Pdrop). The intensity or maximum wind speed is defined as the system's maximum sustained winds. The radius of maximum winds is characterized as the distance from the center of the tropical cyclone to the location of the cyclone's maximum winds. In well-developed hurricanes the radius is found in the inner eyewall, while in subtropical systems, the radius occurs very frequently far away from the center. Lastly, the pressure drop represents the difference between the ambient and central pressures of a tropical system. The space varying wind and pressure on a spiderweb grid is added to the wind input which is then interpolated and combined in and around the cyclone.

Geographical shifts will be applied to the "normal" trajectories of the cyclones, while simultaneously varying the meteorological conditions. The Asoftech Automation Macro Recorder (Asoftech, 2014) was used for the process of creating randomized tropical cyclone ensembles. With its 'Schedule' feature, the macro was set to run at a pre-defined time and repeated indefinitely. A Microsoft Excel sheet was created to define certain reasonable limits for the values of the variables (latitude, 
longitude, Vmax, Rmax, and Pdrop) witnessed in the case study region. The variables were then randomized according the limits so that the ensemble members display correlation between each other, but at the same time result in different possible outcomes.

The first variable established was the tropical cyclones' track position, that is, how its longitude and latitude progress throughout the given time. Normally, as tropical cyclones travel westward, they tend to curve polarward with a continued period of possible tropical systems transitioning to extratropical. At the beginning of the seasonal distribution of the tracks, the delayed warming of the oceans tends to force the location of transition northward, since the critical threshold for tropical development is pushed northward. As the season progresses, after the month of August, the climatologically favored region for baroclinic development expands southward. It is at this point where the trailing ends of tropical cyclones become most threatening in Portugal's case. In order to reproduce trajectories that reach Western Europe, specifically the northern Portuguese coast, the first imposed limitation was that the latitude not surpass a certain limit, selected as $45^{\circ} \mathrm{N}$. The cyclones' paths were selected to begin at a random value between $36,5^{\circ} \mathrm{N}$ and $44,8^{\circ} \mathrm{N}$ latitude. The values were set to increase in random intervals between $0,1^{\circ}$ and $0,3^{\circ}$ if the point's latitude occurred before reaching the turning point. At this point, the trajectory was forced southward so as to hit the Iberian Peninsula. If the point reached the established latitudinal peak, at $45^{\circ} \mathrm{N}$, the values were set to subsequently decrease in random intervals between $0,1^{\circ}$ and $0,5^{\circ}$. The very small variance in the paths' latitudes was to ensure a somewhat direct, or "straight", cyclonic trajectory towards the coast, similar to what is usually witnessed in this region, although these observations are very limited, avoiding a statistical approach to define the storms trajectories estimation.

For the paths' longitudinal values, the tropical cyclone trajectories were set to begin at a random value between $27,0^{\circ} \mathrm{W}$ and $22,5^{\circ} \mathrm{W}$ longitude. The following points were then set to increase in random increments between $0,5^{\circ}$ and $1,0^{\circ}$. Again, the very small variance was imposed in order to try maintain the tropical cyclone path as straight as possible.

With the combination of the longitude and latitude origins, the beginning of the trajectories was established in the region of the Portuguese Azores Islands. This is because it is usually at this point that a lot of the tropical cyclones travel towards Western Europe (Gomes et al., 2018). There are a variety of different tropical cyclone paths that pass through this point. There are tropical cyclones that reach the United States' coast and continue to gain strength and travel across the Atlantic Ocean, and in contrast, there are tropical cyclones that begin in the lower tropics and curve polarward in the midAtlantic very early in their development. The different types of paths are portrayed in Figure 1. Because it is so hard to characterize a "typical" tropical cyclone path, it was opted to simulate the small part of the tropical cyclone that would reach the Portuguese coast, i.e. their tail-ends. It seemed as though it was the component that the tropical cyclones, as a group, had in common.

The next variable was the maximum sustained winds, Vmax. In the region of the Azores Islands, this variable was selected to begin with a random value between 55,0 and 98,0 knots (101,86 and 181,50 $\mathrm{km} / \mathrm{h}$ ) with the attempt to span the various values historically recorded in that area. Because the tropical cyclones that approach the Portuguese coast are typically already transitioning extratropical cyclones with very low intensities, the main particularity to apply to the intensity's definition was that the cyclones' Vmax not reach values below $30 \mathrm{knots}(55,56 \mathrm{~km} / \mathrm{h})$. In decreasing the values of the Vmax, there was careful consideration taken in averting that the wind speed reach bellow the 25 knot mark $(46,30 \mathrm{~km} / \mathrm{h})$, which would lead to the non generation of a spiderweb wind field. This would be equivalent to having a simulation with just the tidal influences acting upon the study area, rendering the simulation useless for ensemble forecasting purposes. The analysis made in this ensemble forecasting is the coast's vulnerability to coastal storms, in other words, coastal storms that will truly impact the shorelines. Because of this, each point's intensity in the storm trajectory was set to decrease in random intervals between 1,0 and 1,5 knots $(1,85$ and $2,78 \mathrm{~km} / \mathrm{h})$ if the previous point was greater than or equal to 30 knots $(55,56 \mathrm{~km} / \mathrm{h})$. If the value decreased so much that it reached 30 knots $(55,56 \mathrm{~km} / \mathrm{h})$, the following point was set to decrease in smaller random intervals between 0,5 and 1,0 knots $(0,93$ and $1,85 \mathrm{~km} / \mathrm{h})($ Gomes et al., 2018). 
The radius of maximum winds was a factor of utmost difficulty to define, especially in this specific region. In the middle of the Atlantic Ocean, there are instances in which the tropical systems can sustain wind speeds of up to $95 \mathrm{knots}(175,94 \mathrm{~km} / \mathrm{h})$, corresponding to a Category 2 Hurricane, as well as, tropical systems with very weak wind speeds, not even reaching $30 \mathrm{knots}(55,56 \mathrm{~km} / \mathrm{h})$. Because the storm's intensity is so varied in this area, specifically around the Azores Islands, the initial attributed Rmax of the tropical cyclone path also needs to greatly vary. A tropical system with a small Rmax produces much more disastrous effects versus the same tropical system with a much larger Rmax. For the ensemble members it was set to begin at any random value between 50 and 125 nautical miles $(92,6$ and $231,5 \mathrm{~km})$. It was then set to increase in random intervals between 0,5 and 1,0 nautical mile $(0,93$ and $1,85 \mathrm{~km}$ ). Because of this great variation, different classes of tropical systems would be observed.

Last of all, the pressure drop, Pdrop, was selected to begin with a random value between 2500 and $6000 \mathrm{~Pa}$. The subsequent points were then set to decrease in random intervals between 100 and $500 \mathrm{~Pa}$, avoiding that the pressure drop reach values below $1000 \mathrm{~Pa}$. If the Pdrop decreased too much, the value was set to consider $2200 \mathrm{~Pa}$ as the value instead, and the process would resume from that value. This way, the value attributed at the beginning of the trajectory would be very varied, capable of reaching up to $6000 \mathrm{~Pa}$, but when getting closer to the Portuguese coast the value would never exceed the 2000 Pa mark (Gomes et al., 2018). With all these randomized variables in the Microsoft Excel sheet defined for this location, the different tropical cyclones' outputs then produced very different mean sea level results, ideal for ensemble forecasting purposes.

Because these natural systems are of such a chaotic nature, the nonlinear errors are common and therefore the application of the ensemble forecast can be of great value. The change in the initial properties of the cyclones can significantly influence the result, therefore a statistical mean of a set of model forecasts can reduce the impact of the initial data uncertainties on the final result. With the application of the implemented methodology, the different outputs should produce significant differences in storm surges values whose distribution should match actual frequency of occurrence.

In the following stage, the numerical results are processed and analyzed. The results of water surface elevation are assessed, in order to examine the envelope of water level, i.e. the maximum storm surge height at predefined locations of the coastal zone, for a given storm. This parameter can be easily linked to potential areas that could be affected by waves overtopping, flooding and coastal erosion. More precisely, for predefined locations, the Maximum Envelope of Water (MEOW) is obtained for a particular storm of a given category. Afterwards, the Maximum of the MEOWs (MOM) is selected for each storm category, among all the maximum storm surge heights of all simulated storms of the same category. There is one MOM per storm category for each location; thus, once the maximum of the maximum envelope of water levels for a given storm category (MOM) is found, it is possible to assess the storm impact for the study area based on this variable. The results obtained are very important to predict the potential consequences of future storm events, and to produce useful information that could be used in the design of emergency plans. In the case of the Portuguese northern coast, there was very little hourly available tide gauge information. Consulting the UHSLC database, only one observation station with available research quality data is found. This station is located in the city of Cascais, Portugal, which is much too far from the area of interest. Because previous applications of Delft Dashboard have shown successful results, with the given careful consideration, these results were also deemed sufficiently accurate. The vulnerability of this region to storminess is assessed based on the recreated storms.

Model domain is characterized by a spatial resolution grid with $96 \times 97$ cells spaced $\sim 10 \mathrm{~km}$ in both directions (Fig. 2-a). The bathymetry is based on a continuous terrain model for ocean and land from General Bathymetric Chart of the Oceans, GEBCO_08 Grid (BODC, 2012). Open boundary conditions and initial conditions are given by TPXO 7.2, the current version of the global model of ocean tides (COAS, 2010). Fig. 2-b shows characteristics of storm Frances occurred in 22-30 October 1992. This is an example of a tropical depression, with wind velocity of $54 \mathrm{~km} / \mathrm{h}$ in the vicinity of the Portuguese territory. 


\section{Results and Discussion}

\subsection{Historical storms affecting Iberian Peninsula}

Because in The Battery, New York, application this methodology showed to be efficient, one would assume that applying the same methodology would result in equally successful simulations in other locations. No historical hurricanes were found to have passed directly in the area of interest. In this case study, only tropical storms and tropical depressions hit the coast. Since the area chosen is usually hit by the trailing end of these tropical systems, the more frequent occurrences are of tropical storms and depressions. Because of Delft Dashboard's spiderweb wind field limitations, very often tropical depressions are unable to be recreated in this setting. Unlike the US case study, a couple of the identified tropical depressions were effectively simulated seeing that tropical depression can sustain winds up to 33 knots $(61,12 \mathrm{~km} / \mathrm{h})$, still within the possible parameters values for the creation of a storm wind field.
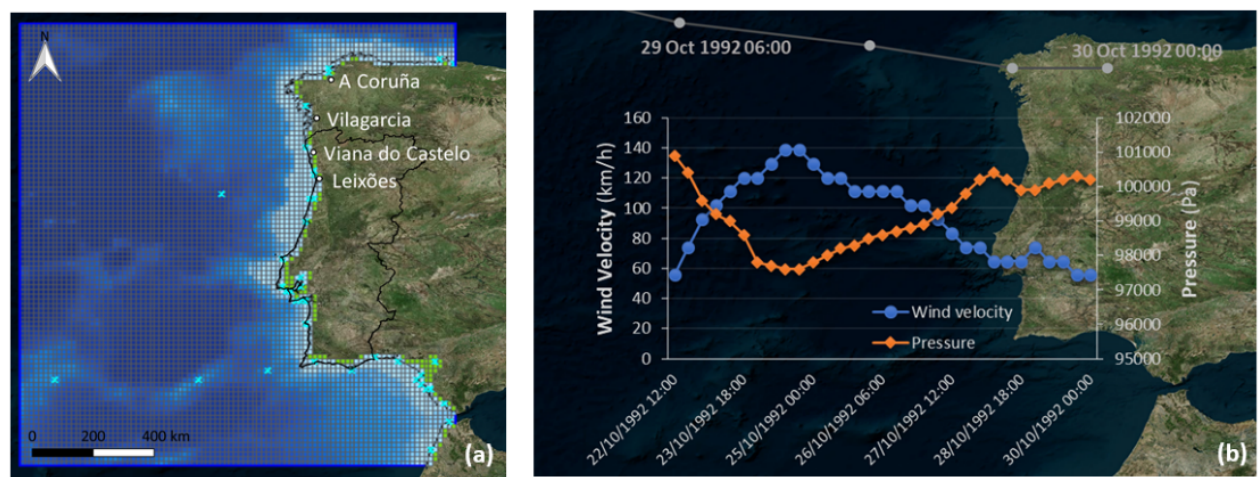

Figure 2: (a) model domain for the Iberian coast, showing the location of observation points (WGS84 coordinate system), and (b) storm Frances 1992 (NOAA, 2012): atmospheric pressure and wind velocity in the eye of the storm.

In this location, the tropical systems do not follow a normal pattern, contrary to the case study area on the other side of the Atlantic Ocean. There are tropical systems that proceed more northward affecting England and Ireland, while others curve polarward much earlier in its development and lean eastward affecting the Azores Island and consequently traveling towards the Iberian Peninsula's direction.

As shown in Table 1, in the vicinity of the Portuguese coast, of the twenty-two identified storms, there were nine identified occurrences of tropical depressions, eleven identified occurrences of tropical storms and only two identified occurrences of tropical cyclones - categorized as Category 1). More intense events, particularly tropical cyclones of higher categories, were not registered. Thus, between 1842 and 2016, for the Portuguese territory, a tropical depression has a probability of occurrence of $50.0 \%$, a tropical storm has a probability of $40.9 \%$ and a tropical cyclone has a probability of $9.1 \%$.

\subsection{Simulation results for Frances storm}

Results for storm Frances 1992 that reached the shore (29 October, 17 h) are presented in Figure 3. Atmospheric pressure was about 1003 mbar and the storm surge was about $0.32 \mathrm{~m}$ height in the vicinity of Vilagarcia. An example of MEOW results that was obtained from the maximum of the envelope of water levels at the observation points are presented at Table 2. For this example of a tropical depression, it is possible to identify a higher flood risk for Vilagarcia location, presenting a maximum storm surge height of $0.88 \mathrm{~m}$. Previous studies have analyzed storm surges in Portugal and verified maximum 
elevations of $1.10 \mathrm{~m}$ for Viana do Castelo during the storm of October 1987 (Gama and Dias, 1994), as well as $0.92 \mathrm{~m}$ for Viana do Castelo and $0.48 \mathrm{~m}$ for Leixões in the storm of January 1937.

Taking into account the MEOW values for other historical coastal storm events in the vicinity of the Portuguese territory and for an ensemble of generated simulations, considering the change of the storm track and the storm intensity, it is possible to obtain the MOM values.

\begin{tabular}{|c|c|c|c|c|}
\hline Name & Year & Start Date & End Date & Velocity $(\mathrm{km} / \mathrm{h})$ \\
\hline \multicolumn{2}{|c|}{ Tropical Depression } & \multicolumn{2}{|c|}{$<62$} & \\
\hline Dolly & 1953 & Sep 8 & Sep 17 & 46 \\
\hline Carol & 1965 & Sep 16 & Oct 1 & 46 \\
\hline Arlene & 1987 & Aug 8 & Aug 28 & 19 \\
\hline Bob & 1991 & Aug 16 & Aug 29 & 19 \\
\hline Frances & 1992 & Oct 22 & Oct 30 & 54 \\
\hline Jeanne & 1998 & Sep 21 & Oct 4 & 54 \\
\hline Vince & 2005 & Oct 8 & Oct 11 & 54 \\
\hline Gordon & 2012 & Aug 15 & Aug 21 & 56 \\
\hline Rafael & 2012 & Oct 12 & Oct 17 & 56 \\
\hline \multicolumn{2}{|c|}{ Tropical Storm } & \multicolumn{2}{|c|}{62 to 118} & \\
\hline Vince & 1842 & Nov 26 & Nov 30 & 93 \\
\hline Not named & 1892 & Sep 3 & Sep 7 & 74 \\
\hline Not named & 1952 & Sep 8 & Sep 12 & 65 \\
\hline Lois & 1966 & Nov 4 & Nov 14 & 81 \\
\hline Chloe & 1967 & Sep 5 & Sep 21 & 81 \\
\hline Irene & 1981 & Sep 21 & Oct 3 & 81 \\
\hline Ivan & 1998 & Sep 19 & Sep 27 & 81 \\
\hline Gordon & 2006 & Sep 10 & Sep 24 & 102 \\
\hline Grace & 2009 & Sep 27 & Oct 6 & 102 \\
\hline Melissa & 2013 & Nov 18 & Nov 21 & 65 \\
\hline Joaquin & 2015 & Sep 28 & Oct 7 & 65 \\
\hline \multicolumn{2}{|c|}{ Cyclone (category 1) } & \multicolumn{2}{|c|}{$\begin{array}{l}119 \text { to } 153 \\
\text { Feb } 15\end{array}$} & \\
\hline Not named & 1941 & Feb 13 & Feb 15 & 130 \\
\hline Xynthia & 2010 & Feb 26 & Mar 3 & 149 \\
\hline
\end{tabular}

Table 1: History of coastal storms in the vicinity of Portuguese northwestern coast (1842-2016), (Gomes et a., 2018).
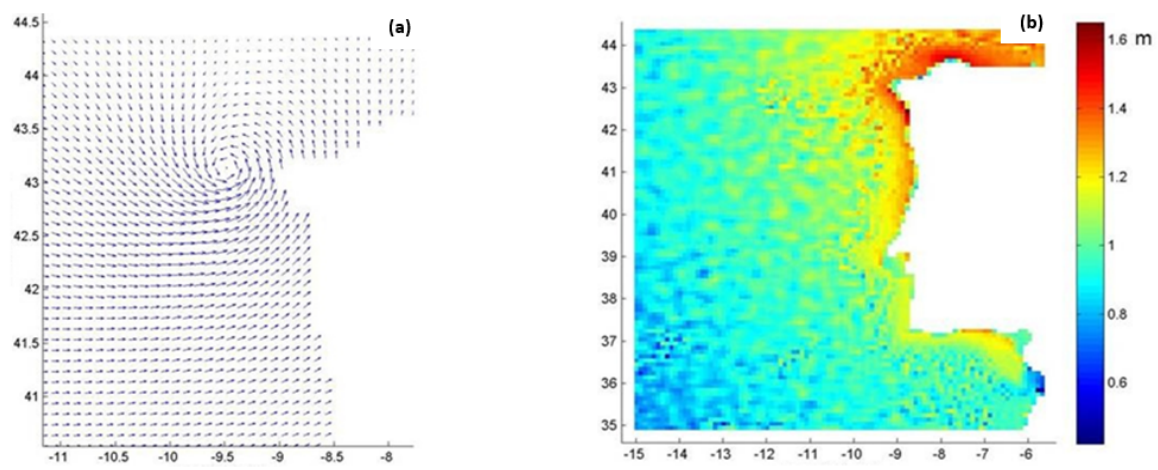

Figure 3: Results of the Frances storm simulation (WGS 84 coordinate system), on October 29, 1992, at 17h: (a) wind 


\begin{tabular}{lcccccc}
\hline Name & Year & Alivés & A Coruña & Vilagarcia & $\begin{array}{c}\text { Viana do } \\
\text { Castelo }\end{array}$ & Leixões \\
\hline Frances & 1992 & 0.01 & 0.14 & 0.88 & 0.07 & 0.12 \\
\hline
\end{tabular}

Table 2: MEOW (maximum storm surge heights in meters), considering an example of historical tropical depression, for different locations along the coast in the Iberian coastal domain.

\section{Conclusion}

The presented case study shows that the adopted methodology allows to reasonably estimate storm surges for the Portuguese coast, namely by the application of DelfDashboard pressure and wind field generation tool associated with tropical storms events. It requires short computational simulation times to assess coastal water surface elevations, proving to be suitable for ensemble simulations. The results of storm surge heights obtained should be considered in coastal risks assessments and of great value to identify the most vulnerable areas. All results obtained, including either simulation of historical storms and ensembles of storms generated by the modification of their characteristics, will provide us relevant information to better evaluate these situations of risk. This solution is also adequate to be implemented in forecasting and warning systems, contributing to the management and planning of coastal zones.

\section{References}

Asoftech (2014) Mouse Keyboard Macro Recorder - Automation Software. Retrieved from Asoftech.com: http://www.asoftech.com/ata/.

BODC (2012). Bathymetry data from the GEBCO_08 Grid available in the DeftDasboard tool.

COAS (2010). TPXO 7.2 - Global inverse tide model available in the DeftDasboard tool.

Deltares (2011). User Manual Delft3D-FLOW. Hydro-Morphodynamics, Version: 3.15, Netherlands, 2011.

Deltares DelftDashboard (2012). - OpenEarth - Deltares Public Wiki. http://publicwiki.deltares.nl/display/OET/ DelftDashboard (2012) accessed Jul 24, 2012.

Dinis, J.L., Tavares, A.O. (2005). Susceptibility geomorphology of the tsunami in Portuguese west coast, Proceedings of the III Congress on planning and management of coastal areas of the Portuguese-speaking countries, Portuguese Association of Water Resources $17 \mathrm{p}$ (in Portuguese).

ECMWF, ERA-40 (2012). http://www.ecmwf.int/research/era/do/get/era-40 (2008) accessed Sept 10, 2012.

Ferreira, Ó., Dias, J.A. (1997). Evaluation of Storms Actions on the West Coast Portugal (Aveiro sector - Cabo Mondego), Collection of Ideas About the Coastal Zone of Portugal, Association Eurocoast - Portugal. Porto 429-447 (in Portuguese).

Gama, C., Taborda, R., Dias, J.A., (1994) Analysis of storm surge in Portugal, between June 1986 and May 1988. Proceedings of Littoral'94, EUROCOAST, (1994), 381-387.

Gomes, M.P., Pinho, J.L.S., Antunes do Carmo, J.S., Santos, L. (2015) - Hazard assessment of storm events for The Battery, New York - Ocean \& Coastal Management. 118, 22-31.

Gomes, M.P., Santos, L., Pinho, J.L.S., Antunes do Carmo, J.S., (2018) Hazard assessment of storm events for the Portuguese northern coast. Journal of Geosciences (in press).

Hart, R.E., Evans, R.E. (2001). A climatology of the extratropical transition of Atlantic tropical cyclones, Journal of Climate, 14 546-564.

Hickey, K. (2011) The Impact of Hurricanes on the Weather of Western Europe, in: A. Lupo (Eds.), Recent Hurricane Research - Climate, Dynamics, and Societal Impacts, InTech, pp. 77-84. 
Holland, G.J. (1980) An analytic model of the wind pressure profiles in hurricanes. Mon.Wea. Rev., $108,1212-1218$.

Keim, B.D., Muller, A.R., Stone, G.W. (2004). Spatial and temporal variability of coastal storms in the North Atlantic Basin, Marine Geology, 210 7-15.

Madsen, H., Jakobsen, F. (2004). Cyclone induced storm surge and flood forecasting in the northern Bay of Bengal. Coastal Engineering, 51, 4, 277-296, ISSN 0378-3839.

Neumann, C.J., Jarvinen, B.R., McAdie, C.J., Elms, J.D. (1993). Tropical Cyclones of the North Atlantic Ocean, Historical Climatology Series, 6-2, National Climatic Data Center, Asheville, NC 1871-1992.

NOAA (2012). Historical Hurricane Tracks. http:csc.noaa.gov/hurricanes accessed Sept 30, 2012.

Santos, L.I.V., Antunes do Carmo, J.S., Pinho, J.L.S. (2012). Influence of the sea level rise on the river mondego estuary, Portugal, Revista Recursos Hídricos. 33, 1, 5-15 (in portuguese). 